\title{
Shocks and Prospects for a Pacific Islands Currency Union
}

\author{
Willie Lahari \\ c/-Economics Department, University of Otago, Dunedin, New Zealand \\ Email:wlahari@gmail.com
}

Received October 5, 2011; revised November 4, 2011; accepted November 13, 2011

\begin{abstract}
This analysis re-kindles the debate on the feasibility of a Pacific Islands currency union in view of the recent expansion and consolidation of regional strategies such as the Pacific Plan and the PACER Plus. Limited consideration has been given to the proposition for a Pacific Islands currency union. This paper exploits the OCA theoretical framework and employs the Gonzalo and $\mathrm{Ng}$ (2001) decomposition method in investigating the dynamic effects of permanent and transitory shocks on key macroeconomic variables among Pacific Island countries (PICs). Using newly constructed quarterly data in the analysis, evidence shows that the proposed union of six PICs (Fiji, PNG, Samoa, Solomon Islands, Vanuatu and Tonga) do not meet most of the preconditions for a union. However, further investigation shows evidence for the Melanesian countries (Fiji, PNG, Solomon Islands and Vanuatu) to possibly form a monetary union, preferably with the Australian dollar as the anchor currency. Nonetheless, further costs in terms of the alignment of policies by Melanesian countries are required.
\end{abstract}

Keywords: Currency Union; Gonzalo and Ng Decomposition; Pacific Island Countries

\section{Introduction}

One of the biggest challenges for Pacific Island countries (PICs) is their vulnerability to shocks such as volatility to commodity and energy prices, frequent cyclones, and political unrests and how they react to these shocks. The negative effects of these shocks have over the years impinged on regional economic growth and development of many of the PICs resulting in sluggish and subdued economic growth, rising unemployment, inflationary pressures and increased poverty levels. According to the Optimal Currency Area (OCA) theory and related extensions flowing from the seminal contributions of Robert Mundell [1], Ronald McKinnon [2], Peter Kenen [3], and Yoshihide Ishiyama [4], and Bayoumi and Eichengreen [5], the effects of these shocks can be mitigated through a mix of OCA properties such as factor mobility and symmetry of shocks when countries enter into a currency union. This provides an economic environment conducive for trade, investment, competition and closer economic integration including policy coordination that leads to stability in prices and output within the union. The main cost of entering into a currency union would be a loss of monetary sovereignty where a country relinquishes full control over monetary policy and the money supply. The challenge for PICs is whether they are ready to enter into a currency union. Hence, this analysis attempts to examine the feasibility for PICs forming a currency union by evaluating the nature and extent of the symmetry of shocks among
PICs which is a key property of the OCA.

Whether the effects of shocks are symmetric (or not), and how PICs respond to these shocks will have implications for the feasibility of a currency union. The continued success or failure of the current regional efforts will also impact on future considerations for a currency union. Such efforts including recent regional plans like the Pacific Plan of 2005 and the current Placer Plus deliberations can be seen as a necessary platform on which to re-kindle the debate on the prospects for a Pacific Islands currency union.

This analysis will focus on six PICs namely, Fiji, Papua New Guinea (PNG), Samoa, Solomon Islands, Tonga and Vanuatu because, firstly, they are fully independent sovereign states. These countries represent about $86 \%$ of the combined total population of all 22 combined PICs and Territories (PICTs), and about $36 \%$ of the total combined gross domestic product (GDP), including $95 \%$ of the total land area of all PICTs. These six PICs have their own currencies, exchange rate regimes and central banks. Hence, they determine their own domestic monetary (and fiscal) policies. Moreover, the six PICs share many common economic and physical characteristics, such as their dependence on imports and development aid, geographic isolation, vulnerability to terms of trade shocks and frequent natural disasters that Economists (see, e.g., [6]) argue are important considerations for a possible currency union.

The work by [5] was one of the first attempts to operationalise the OCA theory, in connection with the symmetry 
property of shocks. The authors applied the Blanchard and Quah [7] decomposing technique within a VAR setup in examining a number of preconditions relating to the behavior of shocks within the European Community (EC) countries and US regions. Their analysis involved assessing the correlations of shocks, magnitudes of shocks, speeds of adjustment of shocks and similarities in the variance decomposition of shocks. The authors found relatively more idiosyncratic shocks across EC countries than across US regions and concluded that the EC may face difficulties to operate within a monetary union, unlike the United States. Similar analyses were undertaken by the same authors as in [8-9], among others, in evaluating the conditions for Europe, Asia and the Americas. Following these studies, many similar studies focusing on various regions of the world emerged, although for the Pacific Island region, there is lack of studies on currency unions relating to the analysis of symmetry of shocks ${ }^{1}$.

This study draws insights from [5,7-9] but applies the decomposition method of Gonzalo and $\mathrm{Ng}$ [14] in decomposing the shocks into its permanent (supply related) and transitory (demand related) components. The application of the decomposing procedure of [7] is not suited for this analysis because it is mainly based on a bi-variate VAR system unlike the approach of [14], which is based on a dynamic system of key macroeconomic policy variables suited for this study. In the [7] technique, arguments are required for imposing structural indentifying restrictions based on economic theory which may be less reliable because the results depend on the types of restrictions imposed on the VAR which differ from study to study. In contrast, the approach of [14] allows for restrictions imposed by the data. Authors such as Cochrane [15] as well as [14], among others, argue that given that we know little or will never know the sources of shocks, applying assumptions about the sources of shocks may have implications on the model outcomes. Hence, the application in this study with newly constructed data extends the empirical scope of the analysis for PICs and is an interesting contribution to the current literature. The OCA theory postulates that countries interested in a currency or monetary union will have to be part of a zone where a single currency circulates or, if there are several exchange rates, their exchange rates are fixed to each other permanently. In the event where two or more countries face symmetric shocks or experience similar effects of shocks, it would be preferable for these countries to apply similar policy responses. In this context, it would be less costly to forego domestic policy autonomy for a common union-wide policy. Hence, entering into a union would facilitate the effective implementation of a com-

\footnotetext{
${ }^{1}$ See related studies for Africa as in [10] and Asia as in [11], among others. For the Pacific Island region, some related but not directly connected studies include $[12,13]$.
}

mon policy among the countries.

\section{Econometric Model and Data}

The Vector Error Correction Model (VECM) incorporates cointegration restrictions on the vector autoregression process in a similar methodological framework to that of [14]. The method provides a systematic framework in identifying and decomposing the permanent and transitory (P-T) shocks among key variables of interest. Thus, the VECM representation of $Z_{t}$ is presented in the reduced form as:

$$
\Delta Z_{t}=\gamma \alpha^{\prime} Z_{t-1}+\Gamma(L) \Delta Z_{t-1}+e_{t}
$$

where $\Delta Z_{t}$ represents first differences of a $n \times 1$ vector of $I(1)$ process of $Z_{i} ; \operatorname{rank}(\pi)=r$ is the number of cointegrated vectors in the system with $\pi=\gamma \alpha^{\prime}$, and $n>r \geq 1$, where $n$ is the number of variables; $\gamma$ is the $n \times r$ matrix of adjustment coefficients or error-correction parameters; $\alpha$ consist of the $r \times n$ cointegrating vectors, and $\Gamma(L)$ is the lag polynomial.

Permanent and Transitory Decomposition

Following from [14], we can generally represent the final-form of the P-T shocks (orthogonalised) from Equation (1) as,

$$
\Delta Z_{t}=\tilde{D}(L) \tilde{\eta}_{t}
$$

where $\tilde{D}(L)$ is a lag polynomial, and $\tilde{\eta}_{t}$ is a $n \times 1$ vector of the transformed orthogonalised P-T shocks. The $\tilde{\eta}_{t} s$ are serially and mutually uncorrelated, and have unit variance. According to Gonzalo and $\mathrm{Ng}$, the $(n-r) \times 1$ vector of shocks, $\tilde{\eta}_{t}^{P}$, are the common stochastic trends or permanent shocks in the VECM when

$\lim _{h \rightarrow \infty} \partial E_{t}\left(Z_{t+h}\right) / \partial \tilde{\eta}_{t}^{p^{\prime}} \neq 0$ for the levels of $Z_{t}$. Similarly, the $r \times 1$ vector of shocks, $\tilde{\eta}_{t}^{T}$, refers to transitory shocks when $\lim _{h \rightarrow \infty} \partial E_{t}\left(Z_{t+h}\right) / \partial \tilde{\eta}_{t}^{T^{\prime}}=0$. The process of decomposing $\tilde{\eta}_{t}$ is summarised as follows: the initial phase involves isolating the structural innovations, denoted as $u_{t}$, from the VECM, distinguished by their "unorthogonalised" permanent and transitory components, denoted as $u_{t}^{P}$ and $u_{t}^{T}$. This is attained by a Wold moving-average representation in the form of Equation (3). Thus, initially, we can generally represent Equation (1) as,

$$
\Delta Z_{t}=C(L) e_{t}
$$

where $C(L)$ is the lag polynomial and $e_{t}$ is an $n \times 1$ vector of the reduced form residuals from the VECM. The task then is to find a matrix $G$ that transforms $e_{t}$ into a set of $u_{t}^{P}$ or $u_{t}^{T}$ shocks ${ }^{2}$. Thus,

$$
G=\left[\begin{array}{c}
\gamma_{\perp}^{\prime} \\
\alpha^{\prime}
\end{array}\right]
$$

\footnotetext{
${ }^{2}$ The application of $G$ is motivated by the Granger Representation Theorem. See Proposition 1, page 1531, in [14] for further discussion.
} 
where $\gamma_{\perp}^{\prime} \gamma=0$, and $\gamma_{\perp}^{\prime}$ is the orthogonal complement to $\gamma$. Since $\gamma_{\perp}^{\prime}$ defines the permanent shocks, $\hat{\gamma}$ can have poor sampling properties. Hence, [14] suggest constraining insignificant estimates of $\hat{\gamma}$ to zero. Not restricting this can result in an unstable process. Thus, we isolate $u_{t}^{P}$ and $u_{t}^{T}$ by computing $G$ with the residuals of the VECM, $e_{t}$, in the form,

$$
G e_{t}=\left[\begin{array}{c}
\gamma_{\perp}^{\prime} e_{t} \\
\alpha^{\prime} e_{t}
\end{array}\right]
$$

where the $(n-r) \times 1$ vector $u_{t}^{P}=\gamma_{\perp}^{\prime} e_{t}$ and $r \times 1$ vector $u_{t}^{T}=\alpha^{\prime} e_{t}$. The next process involves 'orthogonalising' $u_{t}^{P}$ and $u_{t}^{T}$ so that they are mutually uncorrelated. This allows us to obtain the impulse responses and variance decompositions. This is done through obtaining a lower block triangular matrix, $H$, by applying the Choleski decomposition to $\operatorname{cov}\left(G e_{t}\right)$. Thus, the transformation converts $\Delta Z_{t}=D(L) u_{t}$ to arrive at $\Delta Z_{t}=\tilde{D}(L) \tilde{\eta}_{t}$ as in Equation (2) earlier. The transformed orthogonalised P-T shocks are given by,

$$
\tilde{\eta}_{t}=H^{-1} G e_{t}=\left[\begin{array}{l}
\tilde{\eta}^{p} \\
\tilde{\eta}^{T}
\end{array}\right]
$$

The decomposition of the P-T shocks can now be summarised as in Equation (7) below, to arrive at Equation (2) earlier,

$$
\Delta Z_{t}=C(L) G^{-1} H H^{-1} G e_{t}=D(L) H H^{-1} u_{t}==\tilde{D}(L) \tilde{\eta}_{t}(7)
$$

The advantage of the procedure of [14] in our context is that unlike other approaches particularly that of [16] where economic theory is used to identify the short and longrun dynamics of the model, [14] allows for long-run restrictions that are implied by the data. However, this is not limited to economic assumptions. In fact, the method of [14] caters for restrictions on the cointegrating vectors to allow for efficiency gains if the cointegrating restrictions are correct. In addition, [14] examines the dynamic effects of transitory shocks which are embedded within the lower triangular matrix $H$. Given the aforementioned reasons, this approach is suited for this analysis given that it can be quite complicated to ascertain very accurate economic arguments for PICs required for imposing restrictions which may be less reliable. Cochrane [15] argued that despite numerous analyses of the origins of shocks, very little is known about them. A limitation of the procedure of [14] involves the identification of the shocks that are constrained to the cointegration restrictions imposed, as no appropriate rule exists around a subjective choice of $H$, in respect to orthogonalising the structural shocks ${ }^{3}$. It is up to the researcher's considerate application in determining the appropriate number of cointegrating relationships to be imposed. However, in

\footnotetext{
${ }^{3}$ See Assumption 1, page 1532, in [14] for further discussion.
}

practise, this may often be complicated given the model specification requirements, lag criteria and the type of cointegration tests considered.

\section{Data Description}

Time series data for key macroeconomic variables from existing data sources and newly-constructed time series data at a quarterly frequency are employed in this analysis from mainly 1980:1 to $2006: 4^{4}$. The new data includes the newly quarterly real GDP series for the PICs constructed by Lahari, Haug and Ozanne [17]. Table 1 provides a description of the data used in this analysis.

The derivation of other quarterly series follows similar methodology by [17]. In addition, for our purposes, newlyconstructed trade weighted nominal exchange rate indices (TWIs) for each of the PICs are derived and used instead of the exchange rates ${ }^{5}$.

The choice of variables is based on the underlying policy goals, as measured by the variables, of the criteria of the Maastricht Treaty of 1991, and not the specific targets. It is applied in the context of the PICs. This is relevant in respect to setting a benchmark for comparison for PICs which intend to form a currency union. The extent to which a group of countries' policies behave and react to shocks has implications on forming a currency union.

The six PICs together with Australia and New Zealand are clustered into potential union blocks on the basis of their prevailing trade agreements, culture and historical connections. Hence, the following potential groups are proposed: Group 1: Pacific Only (Fiji, PNG, Samoa, Solomon Islands, Tonga and Vanuatu); Group 1A: Pacific with Australia; Group 1B: Pacific with NZ, Group 2: Melanesia (Fiji, PNG, Solomon Islands and Vanuatu); Group $2 A$ : Melanesia with Australia; Group 2B: Melanesia with New Zealand. The challenge is to first examine the possibility of countries in Group 1 (Pacific) forming a currency union. Evaluating initial prospects for uniting the PICs in a union would help distinguish possible prospects for PICs (least developed/developing economies) first, prior to further assessment with Australia and/or New Zealand (advanced/developed economies). Should this hold, then a further examination to form a union with Australia and/or New Zealand is undertaken. If not, then out of the Group 1 countries, a group of Melanesian countries (Group 2) is investigated separately. If forming a union is feasible for Group 2 then further investigation for the prospects of

\footnotetext{
${ }^{4}$ The time-series data for New Zealand, mainly GDP and fiscal (government budget) balance, started from 1987:2 due to the massive financial reforms in the prior years. Hence, where these variables are analysed within a group of countries including New Zealand, the time period will be based on the series for New Zealand.

${ }^{5}$ The use of the TWI based on a common weighting structure of currencies represent a better measure of the degree of economic competitiveness of a country relative to its major trading partners.
} 
Table 1. Data description.

\begin{tabular}{|c|c|c|}
\hline Variable & Description & Source \\
\hline GDP & Log of real gross domestic product (GDP) in 2000 prices. & $\begin{array}{l}\text { Newly constructed series by [17]; and IFS (line 99B.CZF and line } \\
\text { 99BIRZF) for Aust/NZ. }\end{array}$ \\
\hline $\mathrm{CPI}$ & Log of CPI in 2000 prices. & IFS (line 64..ZF). \\
\hline IRATE & Interest rates (gov. bonds). & IFS (line 61..ZF). \\
\hline M2 & Log of money supply adjusted by CPI. & IFS (line 35L..ZF). \\
\hline FGDP & $\begin{array}{l}\text { Ratio of nominal fiscal (gov. budget) balance to nominal GDP. } \\
\text { Fiscal balance is the difference between the nom.gov. expenditure } \\
\text { and revenue. }\end{array}$ & $\begin{array}{l}\text { Newly constructed series following [17]. Data for Australia is from } \\
\text { ABS; NZ is from OECD. }\end{array}$ \\
\hline DebtGDP & Ratio of nominal public external debt to nominal GDP. & $\begin{array}{l}\text { Newly-constructed series following [17]. Data for Australia is from } \\
\text { RBA; NZ is from Statistics NZ. }\end{array}$ \\
\hline TWI & $\begin{array}{l}\text { Log of trade weighted nominal exchange rate index (March quarter, } \\
1980 \text {, base year). }\end{array}$ & $\begin{array}{l}\text { Newly-constructed series; exchange rates IFS (line RH..ZF); } \\
\text { weights: nominal GDP IFS (line 99B..ZF and UN); trade } \\
\text { (COMTRADE). }\end{array}$ \\
\hline TWI-AUD & $\begin{array}{l}\text { Log of trade weighted nominal exchange rate index (March quarter, } \\
1980 \text {, base year) based on Australian dollar as anchor currency. }\end{array}$ & $\begin{array}{l}\text { Newly-constructed series; exchange rates IFS (line RH..ZF); } \\
\text { weights: nominal GDP IFS (line 99B..ZF and UN); trade } \\
\text { (COMTRADE). }\end{array}$ \\
\hline TWI-NZD & $\begin{array}{l}\text { Log of trade weighted nominal exchange rate index (March quarter, } \\
1980 \text {, base year. This is similar to TWI-AUD except that the anchor } \\
\text { currency is the NZ dollar. }\end{array}$ & $\begin{array}{l}\text { Newly-constructed series; exchange rates IFS (line RH..ZF); } \\
\text { weights: nominal GDP IFS (line 99B..ZF and UN); trade } \\
\text { (COMTRADE). }\end{array}$ \\
\hline
\end{tabular}

Notes: Log represents natural logarithms; IFS: International Financial Statistics; OECD: Organization of Economic Cooperation and Development; RBA: Reserve Bank of Australia; RBNZ: Reserve bank of New Zealand; ABS: Australian Bureau of Statistics; UN: United Nations Statistics Division National Accounts; COMTRADE: United Nations Commodity Trade Statistics database.

Group 2 countries forming a currency union with Australia (Group 2A) and/or New Zealand (Group 2B) is undertaken.

\section{Empirical Results}

The empirical findings from the estimation of our model in Section 2 are analyzed in terms of the direction, magnitude, persistence, dominance and correction of P-T shocks within the proposed currency union groupings. Although Table 2 presents separate background tests for the degree of economic convergence (cointegration) (see, e.g., [18]), the cointegration test results themselves form the core input in the estimation of the model ${ }^{6}$. Initial unit root tests revealed that interest rate (IRATE) for Fiji and DebtGDP for Tonga were $I(0)$ and thus their corresponding groupings were excluded in the cointegration tests and model.

\subsection{Group 1 (Pacific)}

A $1 \%$ shock to the system of PICs resulted in some similarities in the impulse response functions although the majority of the results appeared mixed. In Table 3, there was similar direction in the effects of the P-T shocks for real GDP (positive P-shocks) except for Samoa, CPI (positive T-shocks) and TWI (positive T-shocks), except for Tonga. In terms of the magnitudes of shocks, our results

${ }^{6}$ Results for unit roots tests and cointegration are available upon request Other results for the dynamic impulse response functions and variance decompositions by proposed union groups are also available upon request. revealed that the initial impacts were relatively low (less than $1 \%$ ) for all the variables. The low impact is less costly for a union. However, the speed of adjustment of P-T shocks for most of the variables took longer to stabilise or fade away. For example, P-shocks persisted for about $1(h=4)$ year to $3(h=12)$ years for most of the variables while real GDP took about 5 years to just under 8 years before reaching new equilibrium levels. These are costly for a union. Figure 1 shows the dynamic impulse responses for GDP. From the variance decomposition results, the dominance of either a $\mathrm{P}$ or $\mathrm{T}$ shock on economic growth (real GDP) and prices (CPI) appeared mixed. However, only the P-shocks were the key drivers for movements in exchange rates (TWI) while the T-shocks were predominant among prices (CPI) for all PICs, excluding Samoa. Nonetheless, the general findings confirm the lack of coherence in macroeconomic policies. The direct sources for such differences are complex to ascertain but can be generally linked to supply and demand factors. For instance, Samoa and Tonga share some common features such as their dependence on remittances and tourism receipts in contrast to a number of Melanesian countries such as PNG and the Solomon Islands. These factors have a significant influence on Samoa and Tonga's exchange rates in maintaining a consistent flow of foreign reserves. However, this was to some extent inconsistent with the results that showed that their exchanges rates (TWIs) were affected differently. Such dissimilarities are not conducive for a union. It is noted that mainly the fifth transitory shock for real GDP show 
Table 2. Summary of Johansen cointegration test results and degree of convergence by proposed union groups.

\begin{tabular}{|c|c|c|c|c|}
\hline \multirow[b]{2}{*}{ Variables } & \multicolumn{4}{|c|}{ Number of Cointegrating Vectors $(r)^{\mathrm{a}}$} \\
\hline & Group 1 (Pacific $(n=6)$ & Group 2 (Melanesia) $(n=4)$ & $\begin{array}{c}\text { Group 2A } \\
\text { (Melanesia + Aust) }(n=5)\end{array}$ & $\begin{array}{c}\text { Group 2B } \\
(\text { Melanesia + NZ) }(n=5)\end{array}$ \\
\hline DebtGDP (\%) & - & $1^{* *}$ & $1^{* *}$ & $0^{*}$ \\
\hline $\ln (\mathrm{CPI})$ & $1^{* *}$ & $2^{* *}, 3^{*}$ & $4^{* *}$ & $4^{* *}$ \\
\hline $\ln (\mathrm{TWI})$ & $1^{* *}$ & $0^{*}$ & $1^{* *_{\mathrm{c}}}$ & $1^{* * \mathrm{~b}}$ \\
\hline $\ln ($ real GDP) & $4^{* *}, 5^{*}$ & $3^{* *}$ & $3^{* *}$ & $3^{* *}$ \\
\hline \multirow[t]{2}{*}{$\ln ($ real M2) } & $0^{*}$ & $0^{*}$ & $0^{*}$ & $1^{*}$ \\
\hline & & Degree of Convergence ${ }^{\mathrm{c}}$ & & \\
\hline $\begin{array}{l}\text { Complete Convergence } \\
(\mathrm{n}-\mathrm{r}=1) \text { where } \mathrm{r} \neq 0\end{array}$ & Real GDP & Real GDP, CPI & CPI & CPI \\
\hline $\begin{array}{c}\text { Partial Convergence }(n-r \geq 2) \\
\text { where } r \neq 0\end{array}$ & Real GDP & Real GDP, CPI & CPI & $\begin{array}{l}\text { Real GDP, TWI-NZD, } \\
\text { Real M2 }\end{array}$ \\
\hline No Convergence $(r=0)$ & CPI, TWI & DebtGDP & $\begin{array}{l}\text { Real GDP, DebtGDP, } \\
\text { TWI-AUD }\end{array}$ & DebtGDP \\
\hline
\end{tabular}

Notes: ${ }^{a}$ Cointegration results are based on the trace rank test, unless otherwise specified; ${ }^{* *}$ and ${ }^{*}$ represents $5 \%$ and $10 \%$ significance levels respectively; ${ }^{b}$ the maximum-eigenvalue test result was considered as an alternative given the sensitivity of the choice of $r$ imposed on Gonzalo and Ng's method; ${ }^{c}$ when $r$ varies at $5 \%$ and $10 \%$ significance levels, the optimal $r$ was chosen at the $10 \%$ significance level.

Table 3. Direction (+/-) of dynamic impulse response of P-T shocks on initial impact by proposed union groups.

\begin{tabular}{ccccccccc}
\hline \multirow{2}{*}{ Group 1 (Pacific) } & \multicolumn{3}{c}{ Real GDP } & \multicolumn{7}{c}{ CPI } & \multicolumn{7}{c}{ TWI } \\
\cline { 2 - 9 } & P & T & P & T & P & T & \\
\hline Fiji & $(+)$ & $(-)(+)$ & $(+)$ & $(+)$ & $(+)$ & $(+)$ & \\
Vatu & $(+)$ & $(-)(+)$ & $(+)$ & $(+)$ & $(-)(+)$ & $(+)$ & & \\
PNG & $(+)$ & $(-)(+)$ & $(+)$ & $(+)$ & $(+)$ & $(+)$ & & \\
S.I. & $(+)$ & $(-)(+)$ & $(+)$ & $(+)$ & $(+)$ & $(+)$ & & \\
Samoa & $(-)$ & $(-)(+)$ & $(-)(+)$ & $(+)$ & $(-)(+)$ & $(+)$ & & \\
Tonga & $(+)$ & $(-)(+)$ & $(-)(+)$ & $(+)$ & $(+)$ & $(-)$ & & \\
\hline \multirow{2}{*}{ Group 2 (Melanesia) } & Real GDP & \multicolumn{1}{c}{ CPI } & TWI'AUD & DebtGDP \\
\cline { 2 - 9 } & P & T & P & T & P & T & P & T \\
\hline Fiji & $(+)$ & $(-)(+)$ & $(+)$ & $(-)(+)$ & $(+)$ & $(+)$ & $(+)$ & $(+)$ \\
Vatu & $(+)$ & $(+)$ & $(+)$ & $(-)(+)$ & $(+)$ & $(+)$ & $(+)$ & $(+)$ \\
PNG & $(+)$ & $(-)(+)$ & $(+)$ & $(+)$ & $(+)$ & $(+)$ & $(+)$ & $(+)$ \\
S.I & $(+)$ & $(+)$ & $(+)$ & $(+)$ & $(+)$ & $(+)$ & $(+)$ & $(+)$ \\
\hline
\end{tabular}

Notes: PNG: Papua New Guinea; S.I.: Solomon Islands; Vatu: Vanuatu.

no clear pattern of fading. This may be attributed to the sensitivity of cointegrating restrictions as stated by [14].

Table 4 shows mixed correlations of P-T shocks observed for most of the variables except the CPI. These suggest strong asymmetric behaviour among most of the variables except in consumer prices. The outcome shows that it is premature for PICs to form a currency union.

\subsection{Group 2 (Melanesia)}

Our analysis of the variance decomposition results show a considerable degree of similar behaviour in the dominance of either a $\mathrm{P}$ or $\mathrm{T}$ shock for the variables among the majority of Melanesian countries. In particular, the T-shocks were the key drivers for growth (real GDP) and prices (CPI), while the P-shocks were predominant in debt (DebtGDP). This is consistent with economic expectations of transitory factors that impede on economic growth (real GDP) for many Melanesian countries such as volatility to world commodity/mineral prices and demands on tourism receipts. Permanent shocks such as productivity and technological advances appear less significant drivers for growth, although this might change for countries like PNG in the medium to long term given the likely impact of the expanding mineral activities. Furthermore, in Table 3 our findings show common similarities in the direction of the effects of P-T shocks. For instance, the positive effects of P-shocks were predominant among real GDP, CPI and DebtGDP.

The dynamic impulse responses from a $1 \%$ shock to the economy reveal that all P-T shocks for all variables demonstrated minimal initial impact mostly at less than $1 \%$. To a considerable extent, these findings are positive indications for a currency union especially where it facilitates (less costly) implementation of a common union-wide monetary policy. In terms of the persistence of shocks, the duration of the effect of a P-T shock on GDP 

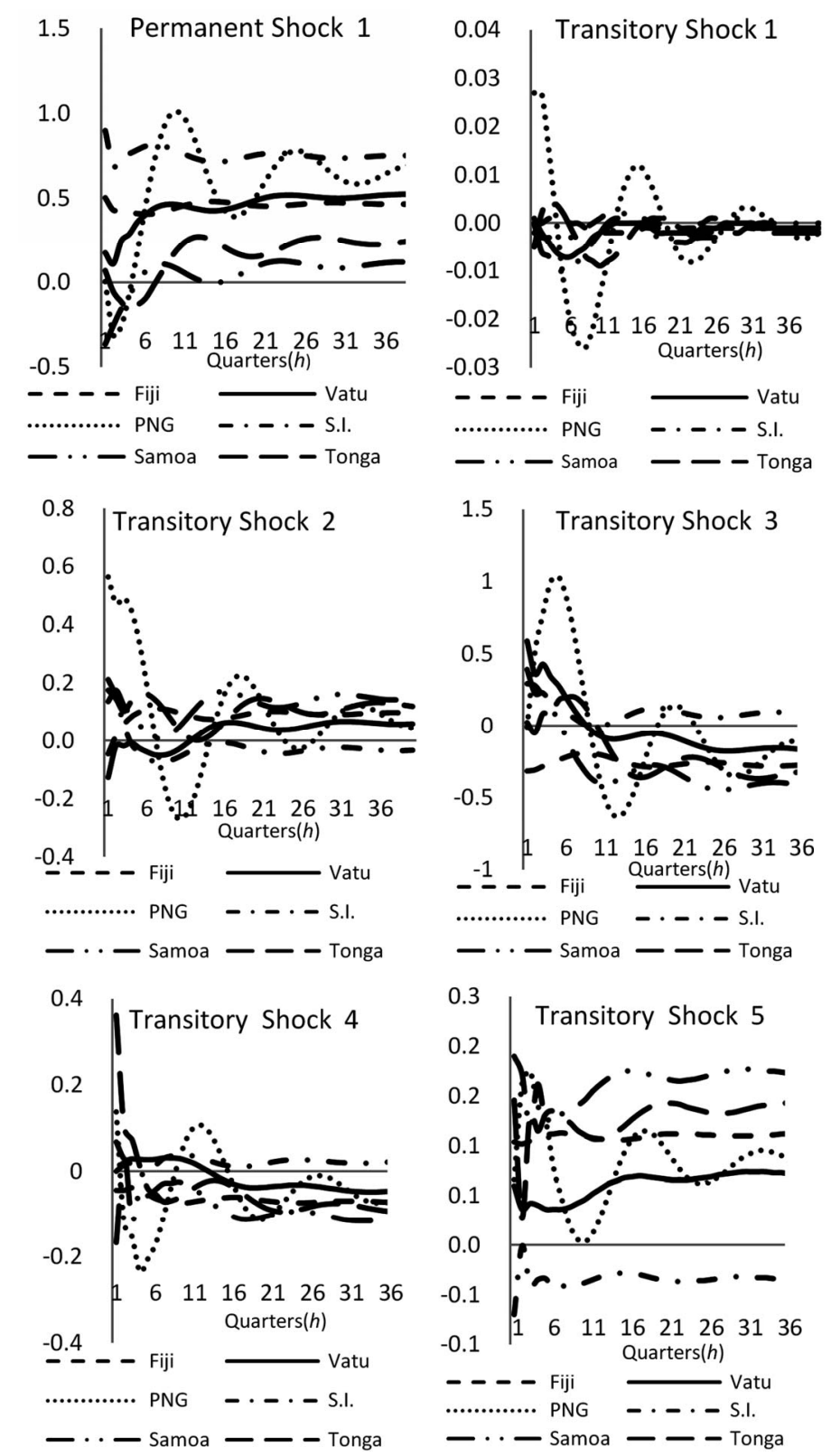

Notes: Vatu: Vanuatu; PNG: Papua New Guinea; S.I.: Solomon Islands.

Figure 1. Dynamic impulse response of P-T shocks for real GDP_Pacific Island countries (Group 1).

and DebtGDP (P-shocks) was about $1(h=4)$ year. For the CPIs (mainly the T-shocks) took between less than 1 year to 2 years on average, noting the case for the Solomon Islands (T-Shock 2 ) that took more than 2 years.

In Table 5, the findings revealed positive correlations in shocks, amidst some negative correlations. Variables such as CPI (except mainly for T-shock 1) and DebtGDP (P-shock 3 and T-shock 1) showed mainly positive correlations supporting conditions for a union. However, there was mixed correlation of shocks for other variables such as GDP and the TWI. Hence, considerations for a union will come at some cost such as major reforms and re- alignment in macroeconomic policies. Since the exchange rate (TWI) shocks appeared more asymmetric, confirming the volatile nature of the exchange rates of the individual Melanesian countries, it is unlikely that a common Melanesian currency fixed on each other's exchange rates or a member's currency should be considered. Instead, a suggestion for an anchor currency such as the Australian dollar should be considered as discussed below in Group $2 A$ (Melanesia + Australia).

In all, the majority of the effects of the P-T shocks show, to some considerable extent, a degree of similar dominance, less magnitude and persistence, which are necessary 
Table 4. Correlation coefficients of impulse responses-P-T shocks: Group 1 (Pacific).

\begin{tabular}{|c|c|c|c|c|c|c|c|c|c|c|c|c|c|c|c|c|c|c|}
\hline & $\mathrm{F}$ & $\mathrm{V}$ & $\mathrm{P}$ & SI & SA & $\mathrm{T}$ & $\mathrm{F}$ & $\mathrm{V}$ & $\mathrm{P}$ & SI & SA & $\mathrm{T}$ & $\mathrm{F}$ & $\mathrm{V}$ & $\mathrm{P}$ & SI & $\mathrm{SA}$ & $\mathrm{T}$ \\
\hline & \multicolumn{6}{|c|}{ (Real GDP) } & \multicolumn{6}{|c|}{ (CPI) } & \multicolumn{6}{|c|}{ (TWI) } \\
\hline & \multicolumn{6}{|c|}{ Permanent Shock 1} & \multicolumn{6}{|c|}{ Permanent Shock 1} & \multicolumn{6}{|c|}{ Permanent Shock 1} \\
\hline $\mathrm{F}$ & 1 & & & & & & 1 & & & & & & 1 & & & & & \\
\hline $\mathrm{V}$ & 0.88 & 1 & & & & & 0.99 & 1 & & & & & 0.74 & 1 & & & & \\
\hline $\mathrm{P}$ & 0.99 & 0.92 & 1 & & & & 0.97 & 0.95 & 1 & & & & 0.99 & 0.79 & 1 & & & \\
\hline SI & 0.97 & 0.94 & 0.98 & 1 & & & 0.83 & 0.87 & 0.77 & 1 & & & -0.99 & -0.81 & -0.99 & 1 & & \\
\hline SA & 0.99 & 0.91 & 0.99 & 0.97 & 1 & & 0.93 & 0.95 & 0.89 & 0.82 & 1 & & 0.42 & 0.92 & 0.5 & -0.53 & 1 & \\
\hline \multirow[t]{2}{*}{$\mathrm{T}$} & 0.92 & 0.97 & 0.95 & 0.97 & 0.93 & 1 & 0.98 & 0.96 & 0.96 & 0.8 & 0.86 & 1 & 0.99 & 0.76 & 0.99 & -0.99 & 0.47 & 1 \\
\hline & \multicolumn{6}{|c|}{ Transitory Shock 1} & \multicolumn{6}{|c|}{ Permanent Shock 2} & \multicolumn{6}{|c|}{ Permanent Shock 2} \\
\hline $\mathrm{F}$ & 1 & & & & & & 1 & & & & & & 1 & & & & & \\
\hline $\mathrm{V}$ & 0.75 & 1 & & & & & 0.98 & 1 & & & & & -0.28 & 1 & & & & \\
\hline $\mathrm{P}$ & 0.61 & 0.75 & 1 & & & & 0.9 & 0.8 & 1 & & & & 0.99 & -0.33 & 1 & & & \\
\hline SI & 0.57 & 0.42 & 0.14 & 1 & & & 0.99 & 0.97 & 0.91 & 1 & & & 0.99 & -0.34 & 0.99 & 1 & & \\
\hline SA & -0.1 & -0.3 & -0.1 & -0.3 & 1 & & 0.9 & 0.96 & 0.74 & 0.92 & 1 & & 0.89 & 0.16 & 0.85 & 0.84 & 1 & \\
\hline \multirow[t]{2}{*}{$\mathrm{T}$} & 0.4 & 0.59 & 0.14 & 0.2 & -0.6 & 1 & 0.99 & 0.94 & 0.94 & 0.98 & 0.84 & 1 & 0.99 & -0.4 & 0.99 & 0.99 & 0.82 & 1 \\
\hline & \multicolumn{6}{|c|}{ Transitory Shock 2} & \multicolumn{6}{|c|}{ Permanent Shock 3} & \multicolumn{6}{|c|}{ Permanent Shock 3} \\
\hline $\mathrm{F}$ & 1 & & & & & & 1 & & & & & & 1 & & & & & \\
\hline $\mathrm{V}$ & 0.02 & 1 & & & & & 0.96 & 1 & & & & & 0.32 & 1 & & & & \\
\hline $\mathrm{P}$ & 0.61 & 0.57 & 1 & & & & 0.97 & 0.99 & 1 & & & & -0.97 & -0.26 & 1 & & & \\
\hline SI & -0.02 & 0.95 & 0.5 & 1 & & & 0.98 & 0.91 & 0.93 & 1 & & & -0.99 & -0.26 & 1 & 1 & & \\
\hline SA & -0.04 & 0.98 & 0.58 & 0.89 & 1 & & 0.95 & 0.99 & 0.99 & 0.9 & 1 & & -0.68 & 0.38 & 0.78 & 0.76 & 1 & \\
\hline \multirow[t]{2}{*}{$\mathrm{T}$} & -0.33 & 0.92 & 0.37 & 0.85 & 0.95 & 1 & 0.99 & 0.94 & 0.97 & 0.98 & 0.94 & 1 & 0.95 & 0.28 & -0.99 & -0.98 & -0.77 & 1 \\
\hline & \multicolumn{6}{|c|}{ Transitory Shock 3} & \multicolumn{6}{|c|}{ Permanent Shock 4} & \multicolumn{6}{|c|}{ Permanent Shock 4} \\
\hline $\mathrm{F}$ & 1 & & & & & & 1 & & & & & & 1 & & & & & \\
\hline $\mathrm{V}$ & -0.61 & 1 & & & & & 0.95 & 1 & & & & & 0.82 & 1 & & & & \\
\hline $\mathrm{P}$ & 0.18 & 0.42 & 1 & & & & 0.74 & 0.73 & 1 & & & & 0.98 & 0.75 & 1 & & & \\
\hline SI & 0.04 & 0.7 & 0.49 & 1 & & & 0.93 & 0.79 & 0.8 & 1 & & & -0.99 & -0.75 & -0.99 & 1 & & \\
\hline SA & -0.27 & -0.03 & -0.7 & -0.1 & 1 & & 0.85 & 0.97 & 0.75 & 0.66 & 1 & & 0.98 & 0.9 & 0.97 & -0.96 & 1 & \\
\hline \multirow[t]{2}{*}{$\mathrm{T}$} & -0.9 & 0.65 & 0.16 & -0.1 & 0.02 & 1 & 0.94 & 0.81 & 0.77 & 0.98 & 0.66 & 1 & 0.95 & 0.63 & 0.99 & -0.98 & 0.91 & 1 \\
\hline & \multicolumn{6}{|c|}{ Transitory Shock 4} & \multicolumn{6}{|c|}{ Transitory Shock 1} & & & ansitor & Shock & & \\
\hline $\mathrm{F}$ & 1 & & & & & & 1 & & & & & & 1 & & & & & \\
\hline V & -0.66 & 1 & & & & & 0.99 & 1 & & & & & 0.35 & 1 & & & & \\
\hline P & -0.23 & 0.3 & 1 & & & & 0.98 & 0.96 & 1 & & & & -0.68 & 0.44 & 1 & & & \\
\hline SI & -0.96 & 0.66 & 0.2 & 1 & & & 0.94 & 0.91 & 0.97 & 1 & & & -0.99 & -0.41 & 0.61 & 1 & & \\
\hline SA & -0.94 & 0.46 & 0.31 & 0.87 & 1 & & 0.99 & 0.99 & 0.94 & 0.89 & 1 & & 0.78 & 0.85 & -0.08 & -0.82 & 1 & \\
\hline $\mathrm{T}$ & -0.52 & -0.2 & -0.02 & 0.56 & 0.55 & 1 & 0.97 & 0.95 & 0.99 & 0.97 & 0.93 & 1 & -0.78 & 0.2 & 0.95 & 0.7 & -0.28 & 1 \\
\hline
\end{tabular}

Notes: F: Fiji; V: Vanuatu; P: PNG; SI: Solomon Islands; SA: Samoa; T: Tonga; due to space limitations, transitory shock 5 results for real GDP are available upon request.

Table 5. Correlation coefficients of impulse responses-P-T shocks: Group 2 (Melanesia).

\begin{tabular}{|c|c|c|c|c|c|c|c|c|c|c|c|c|c|c|c|c|}
\hline & $\mathrm{F}$ & $\mathrm{V}$ & $\mathrm{P}$ & SI & $\mathrm{F}$ & $\mathrm{V}$ & $\mathrm{P}$ & SI & $\mathrm{F}$ & $\mathrm{V}$ & $\mathrm{P}$ & SI & $\mathrm{F}$ & $\mathrm{V}$ & $\mathrm{P}$ & SI \\
\hline & \multicolumn{4}{|c|}{ (Real GDP) } & \multicolumn{4}{|c|}{ (CPI) } & \multicolumn{4}{|c|}{ (DebtGDP) } & \multicolumn{4}{|c|}{ (TWI-AUD) } \\
\hline & \multicolumn{4}{|c|}{ Permanent Shock 1} & \multicolumn{4}{|c|}{ Permanent Shock 1} & \multicolumn{4}{|c|}{ Permanent Shock 1} & \multicolumn{4}{|c|}{ Permanent Shock 1} \\
\hline $\mathrm{F}$ & 1 & & & & 1 & & & & 1 & & & & 1 & & & \\
\hline $\mathrm{V}$ & -1 & 1 & & & 0.93 & 1 & & & 0.95 & 1 & & & 0.99 & 1 & & \\
\hline $\mathrm{P}$ & 0.15 & -0.2 & 1 & & 0.98 & 0.97 & 1 & & -0.6 & -0.8 & 1 & & 0.99 & 0.99 & 1 & \\
\hline SI & 0.86 & -0.8 & -0.3 & 1 & 0.95 & 0.77 & 0.88 & 1 & -0.8 & -0.9 & 0.96 & 1 & 0.99 & 0.99 & 0.99 & 1 \\
\hline & \multicolumn{4}{|c|}{ Transitory Shock 1} & \multicolumn{4}{|c|}{ Transitory Shock 1} & \multicolumn{4}{|c|}{ Permanent Shock 2} & \multicolumn{4}{|c|}{ Permanent Shock 2} \\
\hline $\mathrm{F}$ & 1 & & & & 1 & & & & 1 & & & & 1 & & & \\
\hline $\mathrm{V}$ & 0.25 & 1 & & & -0.9 & 1 & & & -1 & 1 & & & 0.99 & 1 & & \\
\hline $\mathrm{P}$ & -1 & -0.3 & 1 & & 0.45 & -0.2 & 1 & & 0.99 & -1 & 1 & & 0.99 & 0.99 & 1 & \\
\hline \multirow[t]{2}{*}{ SI } & 0.03 & -0.5 & -0.2 & 1 & 0.69 & -0.7 & -0.3 & 1 & -1 & 0.98 & -1 & 1 & 0.99 & 0.99 & 0.99 & 1 \\
\hline & \multicolumn{4}{|c|}{ Transitory Shock 2} & \multicolumn{4}{|c|}{ Transitory Shock 2} & \multicolumn{4}{|c|}{ Permanent Shock 3} & \multicolumn{4}{|c|}{ Permanent Shock 3} \\
\hline $\mathrm{F}$ & 1 & & & & 1 & & & & 1 & & & & 1 & & & \\
\hline V & -1 & 1 & & & 0.99 & 1 & & & 0.95 & 1 & & & 0.99 & 1 & & \\
\hline $\mathrm{P}$ & 0.92 & -0.8 & 1 & & 0.99 & 0.99 & 1 & & 0.97 & 0.85 & 1 & & 0.99 & 0.99 & 1 & \\
\hline SI & 0.19 & 0.05 & 0.46 & 1 & 0.71 & 0.7 & 0.63 & 1 & 0.94 & 0.79 & 0.99 & 1 & 0.99 & 0.99 & 0.99 & 1 \\
\hline & \multicolumn{4}{|c|}{ Transitory Shock 3} & \multicolumn{4}{|c|}{ Transitory Shock 3} & \multicolumn{4}{|c|}{ Transitory Shock 1} & \multicolumn{4}{|c|}{ Transitory Shock 1} \\
\hline $\mathrm{F}$ & 1 & & & & 1 & & & & 1 & & & & 1 & & & \\
\hline V & 0.53 & 1 & & & 0.21 & 1 & & & 0.96 & 1 & & & 0.99 & 1 & & \\
\hline$P$ & 0.55 & -0.4 & 1 & & 0.78 & -0.4 & 1 & & 0.1 & 0.09 & 1 & & 0.99 & 0.99 & 1 & \\
\hline SI & 0.78 & 0.88 & -0 & 1 & 0.72 & 0.74 & 0.2 & 1 & 0.54 & 0.29 & 0.36 & 1 & 0.99 & 0.99 & 0.99 & 1 \\
\hline
\end{tabular}

Notes: See Table 4 notes. 
preconditions for a currency union. However, major policy realignment and reforms are needed noting that although there is strong convergence (cointegration) in prices (CPI), as well as GDP, shown earlier in Table 2, more efforts in terms of aligning market regulations is required so that consumer prices become less persistent. Such reforms would appear timely and draw from the backdrop of over two decades of regional efforts to promote economic co-operation and integration through the auspices of the Melanesian Spearhead Group (MSG) formed in 1993.

\subsection{Group 2A (Melanesia + Australia)}

Although the results show some similarity in variance decomposition of P-T shocks among a majority of variables, these were mainly mixed results. This is expected for real GDP where the Australian economic growth is mainly dominated by P-shocks that reflect mainly supply side factors such as productivity and technological innovations in contrast to the Melanesian economies. There were also mixed results in the direction, magnitude, persistence and correction of P-T shocks. Under such mixed conditions it would be costly for a union.

A positive observation is the hypothetical case for a possible monetary union between Melanesia and Australia in terms of the Australian Dollar being a possible anchor currency for the Melanesian countries. Although the correlation of shocks was generally weak and mixed for most of the variables, this was not the case for the exchange rates (TWI-AUD). This is shown separately in Table 3 corresponding to Melanesia. It is therefore argued that although it would not be feasible for Melanesian countries to form a 'formal' currency union with Australia, the exceptional case is observed in the context of the Melanesian countries adopting the Australian dollar as an anchor currency. Given the highly volatile and weaker currencies of the Melanesian countries, fixing or pegging to the Australian dollar would likely bring about a degree of symmetric movement in their exchange rates. Hence, this would be beneficial for Melanesia mainly in terms of the reduction in exchange rate volatility given that the Australian dollar is a stable regional currency. A number of authors such as [19,20] support the idea of adopting the Australian dollar for a number of Melanesian countries. However, Melanesian countries would have to incur huge costs in terms of harmonising their monetary and fiscal policies to ensure that their policies do not deviate from the monetary policy and exchange rate goals set by Australia. This could be a huge challenge for Melanesian countries in terms of policy discipline and political support.

\subsection{Group 2B (Melanesia + NZ)}

The findings show obvious dissimilarities in the dominating influence of either a $\mathrm{P}$ or $\mathrm{T}$ shock for the majority of variables. The findings also reveal a lack of cohesion in the direction of the effects of P-T shocks. These dissimilarities reflect a degree of asymmetry of shocks and thus pose problems for the effectiveness of a union-wide common policy. Although the magnitudes of the P-T shocks were mainly low (less than 1\%), the corresponding adjustment of the shocks took longer. For example, the P-T shocks for real GDP persisted for 1 to 3 years while the T shocks for real M2 for PNG and the Solomon Islands faded away after $6-7$ years. These conditions imply that a union would incur huge costs. It is also noted that the variance decomposition and impulse responses could not be further analysed for the TWI-NZD for Group $2 B$ countries based on New Zealand as the anchor currency due to poor results attributed to insignificant speed of adjustment coefficients $(\gamma)$. The mixed correlations of P-T shocks amongst most of the variables also indicate asymmetric behaviour of shocks. This suggests that under the current circumstances, adopting the NZ dollar as an anchor currency for Melanesia is not feasible.

\subsection{Standard Errors of the IRF}

The standard errors of the dynamic impulse response functions in our model, based on the bootstrap procedure, are derived based on the restricted model ${ }^{7}$. The overall results for all proposed union groups appear efficient with minimal standard errors that ensured stability in the model consistent with the recommendation of [14]. However, there were a few cases where the standard errors of the P-T shocks were relatively high, attributed to the sensitivity of the cointegration restrictions imposed. For example, for Group $2 A$, the standard errors for CPI were relatively higher for the second and third T-shocks for all countries except from Australia. When tested using the cointegrating rank value, $r$, from the maximum eigenvalue test at $r=2(5 \%$ significance) and $r=3(10 \%$ significance), we found that using $r=3$ with the corresponding restrictions on $\gamma$ resulted in reduced standard errors. Alternatively, this was not the case for the TWI-NZD where testing for an appropriate $r$ resulted in an unstable process. Hence, the results were excluded. This confirms the sensitivity of the appropriateness of the choice of $r$ as stated in [14] and the proposition that the correct $r$ was required. But, as discussed earlier, in practice, this may be difficult given the choice of different cointegration tests involved, lag criteria and model specification that may be considered.

\section{Summary and Conclusion}

This analysis attempts to re-kindle the debate for the

${ }^{7}$ Both the standard errors for the restricted and unrestricted models are available upon request. 
feasibility of a Pacific Islands currency union. Although Pacific Island countries continue to strengthen and revitalise their regional development strategies and agreements such as the Pacific Plan, the agenda for prospects of a currency union has gained little or no support at all. Nonetheless, these strategies provide a strong platform for future considerations for a Pacific or sub-regional currency union. This analysis employed the OCA theoretical framework and applied the decomposition methodology of [14] in evaluating the behaviour of the permanent $(\mathrm{P})$ and transitory $(\mathrm{T})$ shocks among key policy variables. Newly-constructed quarterly time series data were also used in providing new findings to the current debate. The conditions for a currency union were determined by assessing the nature and extent of the symmetric behaviour of P-T shocks. This involved looking at similar dominance of either a $\mathrm{P}$ or $\mathrm{T}$ shock, direction of the effects of P-T shocks, magnitude, persistence and the correlations of P-T shocks. The degree of convergence was also considered. These preconditions were evaluated initially for the Pacific Island countries (PICs) (Group 1). Evidence showed that it was not feasible for the PICs to form a currency union. Further analysis undertaken for the Melanesian countries (Group 2) showed notable evidence that the Melanesian countries had, to a reasonable degree, met necessary macroeconomic conditions for a currency union. However, more structural adjustment efforts are required in realigning and harmonising policies. Evidence also showed that a favorable choice of a currency anchor for Melanesia would be the Australian dollar. It would appear feasible for the Melanesian countries and Australia (Group 2A) to form a monetary union where common monetary policy coordination could be conducted under currency board arrangements, rather than a formal currency union. The evidence for a Melanesian union supports more than two decades of efforts among the Melanesian countries in fostering economic co-operation, even beyond the establishment of the Melanesian Spearhead Group in 1993. The recent setting up of the MSG Secretariat in 2008 only strengthens such efforts for future moves towards a Melanesian union. On the other hand, a currency union of Melanesian countries with New Zealand (Group 2B) would not seem possible at this stage based on the empirical evidence.

\section{Acknowledgements}

I am grateful to Alfred A. Haug for suggesting this study and comments provided. I am also grateful to Arlene Garces-Ozanne and seminar participants of the Economics Department at the University of Otago, for helpful comments and suggestions. I also thank participants at the 3rd Biennial Ocean Development Network Conference in Fiji, April, 2010 for helpful comments. Funding for this research was provided through a Ph.D. scholar- ship award from the New Zealand Agency for International Development.

\section{REFERENCES}

[1] R. Mundell, "A Theory of Optimum Currency Areas," American Economic Review, Vol. 51, No. 4, 1961, pp. 657-665.

[2] R. I. McKinnon, "Optimum Currency Areas," The American Economic Review, Vol. 53, No. 4, 1963, pp. 717-725.

[3] P. Kenen, "Theory of Optimum Currency Areas. An Eclectic View," In: R. Mundell and A. K. Swoboda, Eds., Monetary Problems of the International Economy, University of Chicago Press, Chicago, 1969, pp. 41-60.

[4] Y. Ishiyama, "The Theory of Optimum Currency Areas: A Survey," IMF Staff Papers, Vol. 22, No. 4, 1975, pp. 344-383. doi: $10.2307 / 3866482$

[5] T. Bayoumi and B. Eichengreen, "Shocking Aspects of the European Monetary Integration," In: F. Torres and F. Giavazzi, Eds., Adjustment and Growth in the European Monetary Union, Cambridge University Press, Cambridge, 1993, pp. 193-229. doi:10.1017/CBO9780511599231.014

[6] C. Browne and D. Orsmond, "Pacific Island Countries: Possible Common Currency Arrangement," IMF Working Paper, No. 06/234, 2006, pp. 1-18.

[7] O. J. Blanchard and D. Quah, "Dynamic Effects of Aggregate Demand and Supply Disturbances," American Economic Review, Vol. 79, No. 4, 1989, pp. 655-673.

[8] T. Bayoumi and B. Eichengreen, "One Money or Many? Analyzing the Prospects for Monetary Unification in Various Parts of the World," No. 16, Princeton Studies in International Finance, Princeton, 1994.

[9] T. Bayoumi and B. Eichengreen, "Economic Performance under Alternative Exchange Rate Regimes: Some Historical Evidence," In: P. Kenen, F. Papadia and S. Fabrizio, Eds., The International Monetary System, Cambridge University Press, Cambridge, 1994, pp. 257-297.

[10] D. Fielding and K. Shields, "Modelling Macroeconomic Shocks in the CFA Franz Zone," Journal of Development Economics, Vol. 66, No. 1, 2001, pp. 199-223. doi:10.1016/S0304-3878(01)00161-4

[11] D. Kim, "An East Asian Currency Union? The Empirical Nature of Macroeconomic Shocks in East Asia," Journal of Asian Economics, Vol. 18, No. 6, 2007, pp. 847-866. doi:10.1016/j.asieco.2007.10.002

[12] X. Xu, "The Exchange Rate Regime in Papua New Guinea? Getting It Right," Pacific Economic Bulletin, Vol. 14, No. 2, 1999, pp. 48-60

[13] T. K. Jayaraman and C. Cheer-Keong, "A Single Currency for Pacific Island Countries: A Revisit," Journal of Economic Integration, Vol. 24, No. 2, 2009, pp. 321-342.

[14] J. Gonzalo and S. Ng, "A Systematic Framework for Analyzing the Dynamic Effects of Permanent and Transitory Shocks," Journal of Economic Dynamics and Control, Vol. 25, No. 10, 2001, pp. 1527-1546. doi:10.1016/S0165-1889(99)00062-7 
[15] J. H. Cochrane, "Permanent and Transitory Components of GNP and Stock Prices," Quarterly Journal of Economics, Vol. 109, No. 1, 1994, pp. 241-265. doi: $10.2307 / 2118434$

[16] R. G. King, C. Plosser, J. Stock and M. Watson, "Stochastic Trends and Economic Fluctuations," American Economic Review, Vol. 81, No. 4, 1991, pp. 819-840.

[17] W. Lahari, A. A. Haug and A. G. Ozanne, "Estimating Quarterly GDP for the South Pacific Island Nations," Singapore Economic Review, Vol. 56, No. 1, 2011, pp. 97-112. doi:10.1142/S0217590811004122
[18] A. A. Haug, "Co-Movement towards a Currency or Monetary Union? An Empirical Study for New Zealand," Australian Economic Papers, Vol. 40, No. 3, 2001, pp. 307-317. doi:10.1111/1467-8454.00128

[19] G. De Brouwer, "Should Pacific Island Nations Adopt the Australian Dollar?" Pacific Economic Bulletin, Vol. 15, No. 2, 2000, pp. 161-169.

[20] R. C. Duncan, "Dollarising the Solomon Islands Economy," Pacific Economic Bulletin, Vol. 17, No. 2, 2002, pp. 145-246. 